\title{
Decentralisaties in het lokaal bestuur: bestuurlijke lessen uit Denemarken
}

\author{
Klaartje Peters ${ }^{*}$
}

\section{Inleiding}

In de zomer van 2004 ging het Deense parlement akkoord met regeringsvoorstellen om ingrijpende bestuurlijke hervormingen door te voeren (Regeringen, 2004). De beslissing was het startsein voor een kort maar hevig gemeentelijk herindelingsproces, dat leidde tot een vermindering van 271 tot 98 gemeenten, die fors groter waren dan voorheen. Andere aspecten van de hervormingen waren de reorganisatie van het middenbestuur (vijf regio's in plaats van dertien amter), een ingrijpende herverdeling van taken tussen de drie bestuurslagen en belangrijke veranderingen in de financiële verhoudingen tussen de bestuurslagen. Op 1 januari 2007 ging het nieuwe bestel van start. Elders is in meer detail beschreven wat de hervormingen precies behelsden (Mouritzen, 2007; Van Brunschot \& Fraanje, 2007; Bundgaard \& Vrangbæk, 2007; Blom-Hansen, 2010; Christiansen \& Klitgaard, 2010; Peters, 2012). ${ }^{1}$

In dit artikel zet ik op een rijtje welke voor Nederland relevante inzichten aan de bestuurlijke hervormingen in Denemarken kunnen worden ontleend. De basis daarvoor zijn wetenschappelijke en journalistieke publicaties, overheidsdocumenten en interviews ${ }^{2}$ met onderzoekers, bestuurders, beleidsmakers en journalisten die ik de afgelopen jaren voerde. Natuurlijk kun je de ontwikkelingen in Denemarken niet zonder meer naar de Nederlandse situatie vertalen. Beide landen hebben hun eigen politieke en sociale geschiedenis en hun bijzondere bestuurlijke kenmerken, en de verschillen zijn altijd talrijker dan de overeenkomsten. Maar bij deze constatering kunnen we het naar mijn mening niet laten. Wat hebben we aan de bestuurskunde en andere sociale wetenschappen als de beoefenaren daarvan niet proberen bestuurlijk en maatschappelijk relevante kennis te verzamelen waar beleidsmakers en bestuurders hun voordeel mee kunnen doen? We moeten willen leren van wat er in de landen om ons heen gebeurt, met oog voor de relevante verschillen tussen de landen, zonder te vervallen in wetenschappelijke rigiditeit.

\section{De gemeentelijke herindelingsoperatie}

In juni 2004 neemt de Deense regering de definitieve beslissing over de bestuurlijke hervormingen. Cruciaal onderdeel is de opschaling naar gemeenten van minimaal 20.000 en liefst 30.000 inwoners. ${ }^{3}$ Nog diezelfde zomer, voordat de

* $\quad$ Prof. dr. Klaartje Peters is zelfstandig onderzoeker en publicist en is tevens bijzonder hoogleraar lokaal en regionaal bestuur aan de Universiteit Maastricht. E-mail: info@klaartjepeters.nl. 
benodigde wetgeving door het parlement is behandeld, worden de Deense gemeenten verrast door een bericht uit Kopenhagen: ze krijgen tot 1 januari 2005 de tijd om te voldoen aan de eisen. Als ze dat niet doen, zal dat leiden tot een interventie van de nationale overheid, maar wat die interventie precies behelst wordt nooit duidelijk (Blom-Hansen, 2012, 52).

Op 1 januari 2005 blijkt hoe succesvol de hele operatie is geweest: slechts zeven gemeenten, waarvan vijf kleine eilandgemeenten, voldoen niet aan de eisen. ${ }^{4}$ De 206 gemeenten met minder dan 20.000 inwoners hebben bijna allemaal besloten om te fuseren, en daarmee stijgt de gemiddelde grootte van de Deense gemeenten in één klap van 20.000 naar 55.000 inwoners. Iedereen is verrast door deze uitkomst en de soepele manier waarop het proces zich heeft voltrokken. Wat zijn de lessen die eruit kunnen worden getrokken?

\section{Overvaltechniek heeft gewerkt}

Het is duidelijk dat de Deense regering de gemeenten in de zomer van 2004 volledig heeft overvallen met de eis om binnen een halfjaar aan de nieuwe eisen te voldoen. Dat heeft ertoe geleid dat gemeenten en hun koepelvereniging niet informeerden wat de sancties op het niet-meewerken precies zouden inhouden, laat staan in staat waren afspraken te maken over eventuele sabotagepogingen.

\section{Tijdsdruk heeft gewerkt}

Als gevolg van de enorme tijdsdruk moesten gemeenten direct op zoek naar fusiepartners. Gemeenten werden sterk gedreven door de angst om als enige in een gebied 'over te blijven'. De Deense media gebruikten daarvoor de krachtige metafoor van de huwelijksmarkt. Al aan het eind van de zomer van 2004 waren er elf gemeenten die bekendmaakten fusieovereenkomsten te hebben gesloten. Dat leidde tot een kettingreactie. Binnen de kortste keren waren gemeenten in het hele land ${ }^{5}$ in een onderhandelingsproces met elkaar en hun burgers verwikkeld.

\section{Hervormen gaat makkelijker in goede tijden}

Hoewel er weinig financiële prikkels waren vanuit de nationale overheid, ging de overheveling van taken niet gepaard met bezuinigingen. De bloeiende economie en de gezonde overheidsfinanciën in deze jaren maakten het een aantrekkelijke tijd voor dit type ingrijpende hervormingen.

\section{Burgers zijn wel degelijk betrokken (en niet overal tegen)}

Interessant is de rol die burgers in dit fusieproces hebben gespeeld. In eerste instantie hielden lokale politici en bestuurders hen veelal buiten de besluitvorming, ongetwijfeld ook om de zaken niet nog meer te compliceren in de beperkte tijd die hen was gegund. Maar in 63 gemeenten wisten burgers zich toch met succes een rol in de besluitvorming toe te eigenen (Mouritzen, 2006; Hansen, 2010). Ze deden dit veelal door met petities een referendum af te dwingen. In enkele gemeenten organiseerden burgers zelf een burgerraadpleging en confronteerden ze hun politici vervolgens met de resultaten daarvan. Opvallend is dat burgers, net als de politici, zich niet tegen het fuseren als zodanig verzetten. 


\section{De effecten van de hervormingen}

Wat kunnen we leren als we kijken naar de effecten van de Deense hervormingen? De vraag naar de effecten blijkt een heel lastige. Dat heeft een aantal redenen. De Deense regering heeft ervoor gekozen geen systematisch onderzoek naar de effecten van de hervormingen te doen: geen nulmetingen, geen monitoring en nauwelijks evaluatie. In 2009 publiceerde de regering een 'status report', ${ }^{6}$ dat niet al te veel om het lijf had. De regering had in de aanloop naar de hervormingen ook geen concrete doelstellingen geformuleerd, wat het evalueren er niet gemakkelijker op maakt. En de vraag is of het zin heeft de door de staatscommissie gemaakte probleemanalyse ${ }^{7}$ als uitgangspunt te nemen. Die is volgens diverse insiders niet bepaald objectief geweest: eerst was er de oplossing (afschaffing amter en opschaling gemeenten), en toen zijn pas de problemen geïdentificeerd.

In 2012 is om politieke redenen alsnog besloten om een officiële evaluatie uit te voeren (Økonomi- og Indenrigsministeriet, 2013), maar de vraagstelling daarvan was beperkt en richtte zich met name op de vraag naar de onderlinge afbakening en coördinatie van taken tussen de bestuurslagen.

Het grootste probleem dat uit de evaluatie van 2013 naar voren komt is dat van de 'gespecialiseerde sociale voorzieningen'. Interessant is dat de amter in 2003 en 2004 al waarschuwden voor de overheveling van deze instellingen naar de gemeenten. Dat blijkt terecht: gemeenten zijn hiervoor in feite te klein, kunnen de kosten niet dragen en hebben niet genoeg eigen patiënten om ze te 'vullen'. Ondanks het feit dat er een ingewikkeld systeem op gang is gekomen van gemeenten die tegen betaling elkaars cliënten opnemen, zijn diverse instellingen noodgedwongen gesloten en hebben veel andere grote moeite het hoofd boven water te houden. Gemeenten hebben niet altijd genoeg oog voor de (zeer) kleine doelgroep waarvoor deze voorzieningen bedoeld zijn en besteden hun energie vooral aan de grote groepen cliënten met meer doorsneebehoeften. De mensen die op deze voorzieningen zijn aangewezen, krijgen nu niet altijd de zorg die ze nodig hebben en het rapport beveelt meer nationaal toezicht op en coördinatie van gespecialiseerde voorzieningen aan. Deze conclusie lijkt zeer relevant voor de huidige decentralisaties op het gebied van de jeugdzorg (en mogelijk ook de Algemene Wet Bijzondere Ziektekosten).

Terug naar de vraag naar de effecten. Ondanks een gebrek aan systematische evaluaties is er wel het een en ander bij elkaar te rapen waaruit een beeld ontstaat van de ontwikkelingen sinds 2007.

Interbestuurlijke verhoudingen: nationale overheid versus gemeenten en regio's

De bestuurlijke hervormingen van 2007 waren deels een decentralisatie, met name door de overheveling van veel taken van het middenbestuur naar gemeenten, en deels een centralisatie, doordat ook de nationale overheid taken van de amter overnam en het toezicht op de andere bestuurslagen in een aantal domeinen, met name de gezondheidszorg, versterkte. Maar de greep van de nationale overheid op de gemeenten en regio's is sindsdien in meer opzichten versterkt, zo zeggen betrokkenen. 
Het best zichtbaar is waarschijnlijk de toegenomen centralisatie in de financiële verhoudingen tussen nationale overheid en gemeenten. Dit vraagt om een korte toelichting. De Deense gemeenten (en voorheen ook de amter) halen een aanzienlijk deel van hun inkomsten uit belastingheffing. ${ }^{8}$ Dat klinkt lokale bestuurders in ons land waarschijnlijk als muziek in de oren, maar de nationale overheid in Denemarken heeft de vrijheid van gemeenten op diverse manieren stevig ingeperkt. Een belangrijk middel daarvoor zijn de begrotingsonderhandelingen die de nationale overheid en de belangenorganisaties van de gemeenten jaarlijks voeren, door de Denen 'begrotingssamenwerking' genoemd (Mouritzen, 2007, 14-15). Tijdens die onderhandelingen worden afspraken gemaakt over de gewenste ontwikkeling van de uitgaven en inkomsten van gemeenten. De afspraken zijn niet afdwingbaar, maar hebben in slechte tijden wel altijd matigend gewerkt.

Vanaf het moment dat de liberalen en conservatieven op nationaal niveau in 2001 de macht van de sociaaldemocraten overnamen, is er spanning op de begrotingssamenwerking komen te staan. De regering verordonneerde dat de gemeentelijke belastingtarieven niet mochten stijgen (op geaggregeerd niveau), en in de jaren vóór 2007 werden de duimschroeven nog wat strakker aangedraaid en gold dat verbod ook voor elke individuele gemeente. Dat was mede bedoeld om te voorkomen dat gemeenten in de periode vóór de fusies nog snel hun uitgaven drastisch zouden verhogen.

In 2007, het eerste jaar van het nieuwe stelsel, liet de regering zoals beloofd de teugels vieren en bood de jaarlijkse begrotingsovereenkomst weer enige ruimte voor verhoging van uitgaven en belastingheffing. De schok was groot toen enkele maanden later duidelijk werd dat de afspraken door de gemeenten massaal en grootschalig werden geschonden. ${ }^{9}$ Dit was aanleiding voor de nationale overheid om fors in te grijpen. In het voorjaar van 2008 werden wettelijke sancties ingevoerd. Zowel te hoge begrotingen als te veel belastingheffing leidden tot kortingen op de uitkeringen voor gemeenten, zowel voor de betreffende gemeenten als collectief. De sancties werden in de jaren daarna stapsgewijs versterkt. Toen de begrotingen voor 2009 weer in lijn bleken te zijn met de gemaakte afspraken, leek het erop dat de sancties werkten. Maar in de loop van 2010 werd duidelijk dat de begrotingsoverschrijdingen over het jaar enorm waren geweest, bij elkaar 5 miljard DKK. Ook daar werden sancties voor afgekondigd. In 2012 werden onder invloed van de Europese regels voor het EMU-tekort (Europese Monetaire Unie) de wettelijke sancties op het schenden van de budgetafspraken en op begrotingsoverschrijdingen opnieuw aangescherpt.

De autonomie van het lokaal bestuur is in financiële zin al met al fors ingeperkt (Blom-Hansen, 2012). De vraag is natuurlijk of dit verband houdt met de hervormingen van 2007. Het korte antwoord is: niet rechtstreeks, maar de hervormingen hebben ingrepen wel vergemakkelijkt omdat gemeenten druk waren met de enorme uitdagingen op lokaal niveau en omdat de interbestuurlijke verhoudingen sowieso aan grote veranderingen onderhevig waren. En net als voor het middenbestuur geldt misschien dat 98 grote, professionele gemeenten makkelijker zijn te beheersen en te sturen dan 271 veelal kleine gemeenten. Dit is een interessant punt voor nader onderzoek. 
Volgens sommigen van mijn gesprekspartners zijn de verhoudingen tussen gemeenten en binnen hun belangenvereniging Kommunernes Landsforening (KL) overigens ook sterk veranderd: de nieuwe, grotere gemeenten zijn professioneler en mondiger, en maken steeds vaker rechtstreeks afspraken met de ministeries, buiten $\mathrm{KL}$ om. De afspraken die KL maakt met de nationale overheid worden door de leden niet zonder meer goedgekeurd. Voor KL levert dat nieuwe problemen en dilemma's op. Dat zijn ontwikkelingen die de Vereniging van Nederlandse Gemeenten zonder twijfel herkent. Als de eenheid binnen KL afneemt en er barsten in het gemeentelijk blok ontstaan, kan dat - maar nu ben ik aan het speculeren - ertoe leiden dat de centralisatietendens wordt versterkt. Ook dit is een interessant punt voor nader onderzoek.

Interbestuurlijke verhoudingen: regio's en gemeenten

Op het terrein van de gezondheidszorg moeten regio's en gemeenten intensief samenwerken. Regio's doen de ziekenhuiszorg en gemeenten de aanverwante zorg, zoals revalidatie, thuiszorg en preventieve zorg. Elke regio sluit met de inliggende gemeenten wettelijk verplichte overeenkomsten over de afbakening van verantwoordelijkheden, samenwerking, prestatieafspraken en de daarmee verbonden financiële aspecten. Regio en gemeenten nemen deel aan wettelijk verplichte coördinatiecommissies, waar ook de sector zelf bij betrokken is. Ook vóór de hervormingen was er afstemming nodig, maar het feit dat de zorg nu verdeeld is tussen regio's en gemeenten heeft geleid tot een uitbreiding van het aantal overlegvormen, op diverse niveaus (KL, Danske Regioner \& Indenrigs- og Socialministeriet, 2009, 33-35).

In de Status for the Implementation of the Local Government Reform van 2009 rapporteren de gezamenlijke overheden dat in de korte tijd dat het stelsel bestaat aanzienlijke verschillen zijn ontstaan tussen gemeenten in de uitgaven voor de zorg en in het gebruik dat burgers van de voorzieningen maken. Het (voorspelbare) gevolg was dat de nationale overheid zich op allerlei manieren is gaan bemoeien met het monitoren, onderzoeken en verklaren van de verschillen, en zelf of met behulp van commissies gemeenten wil laten meedenken over manieren om de kosten in de hand te houden en zaken te verbeteren. Ook hier geldt misschien dat dit soort mechanismen eerder in werking treedt bij 98 professioneel opererende gemeenten dan in de oude situatie.

De officiële evaluatie van maart 2013 gaat uitgebreid in op de stand van zaken op de vier onderzochte beleidsdomeinen: de gezondheidszorg, milieubescherming, regionale ontwikkeling en gespecialiseerde sociale voorzieningen. Het is niet eenvoudig om er een totaalbeeld uit op te maken. De evaluatiecommissie spreekt op geen enkele manier een eindoordeel uit over de vraag hoe goed of slecht het eigenlijk gaat. Op alle terreinen is sprake van zoeken naar samenwerking en afstemming, en overal is ruimte voor verbetering. Zo wordt op het terrein van de gezondheidszorg duidelijk dat de afstemming tussen de ziekenhuiszorg en de bij gemeenten ondergebrachte vormen van zorg nog niet goed genoeg loopt. De beschrijvingen, en de constatering dat de bestuurlijke betrokkenheid van de regio's hier niet veel meerwaarde heeft, doen sterk denken aan de beschouwingen over de jeugdzorg in Nederland van enkele jaren geleden. Volgens sommige 
gesprekspartners is de conclusie over de afstemmingsproblemen in de zorgsector illustratief voor de interbestuurlijke verhoudingen in Denemarken. Een veranderde taakverdeling is niet per se een betere taakverdeling: sommige afstemmingsproblemen zijn verdwenen, maar er zijn ook nieuwe ontstaan.

\section{Efficiency in het lokaal bestuur}

Een van de weinige aspecten van de bestuurlijke hervormingen waar inmiddels enig effectonderzoek naar is verricht, betreft de vermeende efficiencyverbetering van de gefuseerde gemeenten. Het economies of scale-argument was dan ook een veelgebruikt argument in de besluitvorming over de hervormingen, door voorstanders van gemeentelijke opschaling én door de staatscommissie die de hervormingen voorbereidde. ${ }^{10}$ Vanaf 2007 hadden onderzoekers in Denemarken de kans om de kostenontwikkeling van gefuseerde en niet-gefuseerde gemeenten te vergelijken. De twee wetenschappelijke studies die gedaan zijn (Krevi, 2011; Blom-Hansen, Houlberg \& Serritzlew, 2012; zie ook Blom-Hansen, 2012, 65-67) laten zien dat gefuseerde gemeenten minder kosten maken dan niet-gefuseerde gemeenten. Daarbij is alleen gekeken naar bestuurskosten. ${ }^{11}$ Voor beide groepen gemeenten geldt overigens dat de uitgaven in 2008 en 2009 sterk opliepen, en daarna weer begonnen te dalen, als gevolg van de financiële crisis en de door de Deense regering genomen maatregelen. Het vanaf 2007 ontstane verschil tussen gefuseerde en niet-gefuseerde gemeenten blijft daarbij echter intact.

Deze onderzoeksresultaten weerspreken de (recentelijk) veelgehoorde opvatting dat gemeenten na fusies of herindeling altijd meer geld gaan uitgeven, bijvoorbeeld aan een nieuw groot gemeentehuis of aan hogere salarissen voor bestuurders en politici. Ook uit Nederlands onderzoek (Allers \& Geertsema, 2012) blijkt dat de uitgaven van heringedeelde gemeenten in Nederland hoger zijn dan die van andere gemeenten. De beschikbare onderzoeksresultaten spreken elkaar dus tegen, moet de onbevredigende conclusie zijn. Dat is overigens ook de conclusie die de Deense onderzoekers trekken uit al het verzamelde onderzoek (in binnenen buitenland, en over de laatste decennia) naar dit thema (Blom-Hansen e.a., 2012).

\section{Lokale democratie}

Een laatste interessant thema waar enig onderzoek naar is gedaan, betreft de gevolgen van de hervormingen voor de kwaliteit van de lokale democratie. Zowel in Nederland als in Denemarken speelt dat onderwerp een belangrijke rol in de discussies over decentralisatie en het al dan niet opschalen van gemeenten. In die discussies wordt het onderwerp meestal opgebracht door tegenstanders van schaalvergroting, en de stelling is dan dat de lokale democratie zal lijden onder een fusie/opschaling/herindeling van gemeenten.

Naar de relatie tussen schaalgrootte en democratie is in de politieke wetenschappen relatief veel onderzoek gedaan. De opbrengsten daarvan zijn uiteindelijk altijd enigszins teleurstellend. Het blijkt dat over dit onderwerp eigenlijk geen algemene uitspraken kunnen worden gedaan. Afhankelijk van de gekozen definitie van het begrip democratie kan alles worden bewezen: dat grote gemeenten democratischer zijn dan kleine, maar ook precies het tegenovergestelde. Maar 
met wat goede wil kunnen we een paar dingen vaststellen, zo blijkt uit een inventarisatie die ik eerder maakte (Peters, 2010). ${ }^{12}$ In kleine gemeenten is de opkomst bij verkiezingen significant hoger dan in grotere gemeenten. ${ }^{13} \mathrm{Als}$ we democratie in iets bredere (ook participatieve) zin definiëren, wordt het beeld diffuser. De verschillende (internationale) onderzoeken spreken elkaar dan tegen, of leiden in elk geval tot verschillende conclusies. Er zijn studies waaruit blijkt dat participatie afneemt naarmate gemeenten groter zijn (Denters \& Rose, 2008; Rose, 2002). Maar er zijn ook tegenovergestelde uitkomsten bekend: in de besluitvorming over de bestuurlijke hervormingen in Denemarken was een grootschalig onderzoek naar deze vraag (Kjaer \& Mouritzen, 2003) - met als uitkomst dat grote gemeenten niet minder democratisch zijn dan kleine gemeenten - een belangrijk argument voor de regering om de gemeentelijke opschaling door te (kunnen) drukken. Een andere vraag is die naar de gevolgen van herindelingsprocessen voor de staat van de lokale democratie. ${ }^{14}$ Uit de genoemde inventarisatie blijkt dat ook hierover geen eenduidige conclusie valt te trekken. Er is weinig onderzoek gedaan naar de vraag of de betrokkenheid van burgers bij herindeling afneemt of niet, en datgene wat er ligt levert een gemengd beeld op. Wél is het zo dat uit meerdere onderzoeken blijkt dat herindeling een (waarschijnlijk tijdelijk) negatief effect heeft op de opkomst bij lokale verkiezingen.

In Denemarken zijn enkele wetenschappelijke onderzoeken gedaan naar de gevolgen van de recente gemeentelijke fusies. Op het eiland Bornholm, waar de vijf gemeenten al in 2003 fuseerden, vonden onderzoekers aanwijzingen dat de lokale democratie er op een aantal aspecten na de fusie slechter voor stond, maar ook dat er na enkele jaren verbetering leek te zijn (Kjaer \& Olsen, 2004, 2006). Een tweede onderzoek richtte zich op alle Deense gemeenten (Lassen \& Serritzlew, 2011). Na de hervormingen van 2007 hadden burgers volgens Deense politicologen minder vertrouwen in het politieke systeem en hun mogelijkheden om invloed uit te oefenen ${ }^{15}$ dan vóór de hervormingen.

\section{Tot slot}

In veel opzichten bieden de Deense hervormingen antwoorden op vragen die we ons in Nederland stellen. Geen definitieve antwoorden, maar we kunnen er zeker van leren. De Deense casus blijft de komende jaren ongetwijfeld een bron om uit te putten.

\section{Noten}

1 Zie voor Engelstalige informatie van overheidswege: Indenrigs- og Sundhedsministeriet (2005) en KL, Danske Regioner \& Indenrigs- og Socialministeriet (2009).

2 Deels ook interviews door anderen, in het bijzonder Jorrit de Jong en Annemieke van Dam.

3 Het alternatief is vergaande bindende intergemeentelijke samenwerking.

4 Hiervoor wordt in de daaropvolgende jaren een oplossing gevonden. 
5 Behalve in de Kopenhagenregio, aangezien de meeste gemeenten daar groter zijn dan 20.000 inwoners.

6 In het voorjaar van 2010 verscheen de Engelstalige versie: Status for the Implementation of the Local Government Reform in 2009.

7 Strukturkommission (2004).

8 Vóór de hervormingen ruim de helft van hun inkomsten (57,8 procent in 2003), daarna iets meer.

9 Hun begrotingen voor het jaar 2008 waren tezamen meer dan 1 miljard DKK ( $€ 134$ miljoen) hoger dan afgesproken, en de geraamde belastinginkomsten waren zelfs 1,5 miljard DKK hoger.

10 Alleen al in de Engelstalige samenvatting van het rapport van de Strukturkommission uit 2004 komt de term 29 keer voor.

11 Hieronder vallen: salariskosten (75 procent), onderhoud gebouwen, inkoop kantoorbenodigdheden, verzekeringen, vergoedingen politici.

12 Het betreft een inventarisatie van onderzoek door anderen, onder meer Beerepoot, Fraanje \& Herweijer (2009) en Denters \& Rose (2008).

13 Kanttekening daarbij is wel dat dit niet alleen voor lokale, maar voor alle verkiezingen (dus ook provinciale, landelijke en Europese) geldt.

14 Als het zo is dat grotere gemeenten (iets) minder democratisch zijn dan kleinere gemeenten, heeft herindeling een zeker negatief effect op de kwaliteit van de democratie. Herindeling leidt immers tot meer grote en minder kleine gemeenten. Dit is dus een indirect effect. Maar de vraag is hier of herindeling ook een direct effect heeft op de kwaliteit van de democratie.

15 De gebruikte indicator is political efficacy, het vertrouwen van burgers in het politieke systeem en het geloof dat ze de politieke besluitvorming kunnen begrijpen en beïnvloeden.

\section{Literatuur}

Allers, M., \& Geertsema, B. (2012). Kabinet rekent zich rijk met gemeentelijke opschaling. Me Judice, 9 november.

Beerepoot, R., Fraanje, R., \& Herweijer, M. (2009). Processen en effecten van herindeling. Alphen a/d Rijn: Kluwer.

Blom-Hansen, J. (2010). Municipal Amalgamations and Common Pool Problems: The Danish Local Government Reform in 2007. Scandinavian political Studies, 33 (1): 51-73.

Blom-Hansen, J. (2012). Local government in Denmark and the 2007 municipal reform. In: A. Moisio (Ed.), Rethinking local government: Essays on municipal reform (VATT Publications). Helsinki: Government Institute for Economic Research.

Blom-Hansen, J., Houlberg, K., \& Serritzlew. S. (2013). Size, Democracy and the Economic Costs of Running the Political System. American Journal of Political Science, 2013.

Brunschot, A. van, \& Fraanje, R. (2007). Hervormingsproces Deense centrale overheid. Openbaar Bestuur, 17 (4): 7-11.

Bundgaard, U., \& Vrangbæk, K. (2007). Reform by Coincidence? Explaining the Policy Process of Structural Reform in Denmark. Scandinavian Political Studies, 30 (4): 491-520.

Christiansen, P.M., \& Klitgaard, M.B. (2010). Behind the Veil of Vagueness. Success and Failure of Institutional Reforms. Journal of Public Policy, 30 (2): 183-200. 
Dam, A. van (2007). Could the little mermaid survive in Dutch waters? A study of the pros and cons of copying the Danish Administrative Reform in the Netherlands. Den Haag: NSOB.

Denters, B., \& Rose, L.E. (2008). Municipal Size and Local Political Participation: Findings from Switzerland, Norway, Denmark and the Netherlands (APSA working paper).

Hansen, K.M. (2010). Borgerinddragelse - et komparativt studie af borgerinddragelsen i regioner og kommuner. Odense: Syddansk Universitetsforlag.

Indenrigs- og Sundhedsministeriet (2005). The Local Government Reform in brief. Kopenhagen: Indenrigs- og Sundhedsministeriet.

Kjær, U., \& Mouritzen, P.E. (2003). Kommunestørrelse og lokaldemokrati. Odense: Syddansk Universitetsforlag.

Kjær, U., \& Olsen, L. (2004). Kommunesammenloegningens første år bedømt af borgerne på Bornholm. Kopenhagen: AKF forlaget.

Kjær, U., \& Olsen, L. (2006). Bornholmerne og demokratiet efter kommunesammenloegningen. Kopenhagen: AKF forlaget.

Krevi (2011). Kommunernes administrative ressourceforbrug - udviklingen 2006-2010. Aarhus: Krevi.

Lassen, D.D., \& Serritzlew, S. (2011). Jurisdiction Size and Local Democracy: Evidence on Internal Political Efficacy from Large-scale Municipal Reform. American Political Science Review, 105 (2): 238-258.

Mouritzen, P.E. (2006). Stort er godt. Otte fortaellinger om tilblivelsen af de nye kommuner. Odense: Syddansk Universitetsforlag.

Mouritzen, P.E. (2007). Reforming Local Government in Denmark: How and Why? Món Local Studies, Centre for Local Innovation, Barcelona.

Mouritzen, P.E., Bundgaard, U., \& Vrangbæk, K. (2007). Reform by Coincidence? Explaining the Policy Process of Structural Reform in Denmark. Scandinavian Political Studies, 30 (4): 491-520.

Økonomi- og Indenrigsministeriet (2013). Evaluering af kommunalreformen. Kopenhagen: Økonomi- og Indenrigsministeriet.

Peters, K. (2010). Gemeentelijke schaalvergroting en het democratie-argument. In: Het huis van de democratie na de gemeenteraadsverkiezingen: achterstallig onderhoud? (Jaarboek 2010 Vereniging van Griffiers). Den Haag: Sdu uitgevers.

Peters, K. (2011). Prikkels voor bestuurlijke dynamiek. Lessen uit Denemarken. In: J. Saris, P. van Ree, J. Modder \& M. Stamsnijder, Stedelijke regio's. Over informele planning op een regionale schaal. Rotterdam: NAi Uitgevers, 247-253.

Peters, K. (2012). A Window of Opportunity. Institutional Reform in Denmark. In: S. Cels, J. de Jong \& F. Nauta (Eds.), Agents of Change. Strategy and Tactics for Social Innovation. Washington DC: Brookings Institution Press and Ash Institute For Democratic Governance and Innovation of the Harvard Kennedy School of Government.

Regeringen (2004). Agreement on a Structural Reform. Kopenhagen: Regeringen.

Rose, L.E. (2002). Municipal Size and Local Nonelectoral Participation: Findings from Denmark, The Netherlands and Norway. Environment and Planning C: Government and Policy, 20: 829-851.

KL, Danske Regioner \& Indenrigs- og Socialministeriet (2009). Status for the Implementation of the Local Government Reform in 2009. Kopenhagen: KL, Danske Regioner \& Indenrigs- og Socialministeriet.

Strukturkommission (2004). Recommendation of the Commission on Administrative Structure-Summary. Kopenhagen. 